\title{
Forecasting National Well-being Indicators of Taiwan
}

\section{Huang $\mathrm{CY}^{1}$, Lo $\mathrm{YY}^{2}$ and Chen $\mathrm{Cl}^{3 *}$}

${ }^{1}$ Department of Nursing, I-Shou University, Taiwan

${ }^{2}$ Department of Healthcare Adminstration, I-Shou University, Taiwan

${ }^{3}$ Department of Industrial Management, I-Shou University, Taiwan

\begin{abstract}
Newly proposed National Well-being Indicators from Taiwan government is investigated in research. These indicators are categorized into two categories and 11 topics based on the OECD's Your Better Life Index. Three indicators which are consumption expenditure per capita, unemployment rate of age 15 to 24 and real earning are analyzed by grey forecasting model because of complete information provided. The result showed that consumption expenditure will increase, unemployment rate will keep at above $13 \%$ and real earning will decrease constantly in the future four year. The government should propose policies to prevent economic downturn in advance.
\end{abstract}

Keywords: Grey model (1,1); National well-being indicators; Unemployment; Consumption expenditure

\section{Introduction}

The responsibility of a government is to bring economic prosperity and well-beings for his people. Traditionally, government will announce statistical figures to show the status of economic situation and the level of people' living standard, for example, gross domestic product (GDP), consumer's price index (CPI), and so on. Unfortunately, people do not feel directly from these figures because these are macro-economic figures. People feel directly from his everyday lives, for example the food price, house price, rent, salary, employment and social security. It happens all the time that people are angry and complaint about government incapability when positive economic figures announced. The gap between government administration and people awareness is always an issue to solve. Therefore, concerns have emerged to develop new indicators which are beyond GDP and more inclusive of environmental and social aspects of progress. In order to comply with international trend, the Directorate-General of Budget, Accounting and Statistics (DGBAS) has been working on developing better measurements of well-being and progress. The National Wellbeing Indicators (NWI) in Taiwan were derived from the OECD "Your Better Life Index's (BLI's)" There are 11 topics categorized into material living conditions which includes housing, income, jobs and quality of life matters which includes community, education, environment, civic engagement, health, life satisfaction, safety and work-life balance. For purposes of comparison, the international indicators and domestic indicators coexist in the NWI. The National Well-being Indicators in Taiwan is shown in Table 1. The outcomes of National Well-being Indicators were first launched in August 2013 and their effect on how people feel has not reported which intrigues us studying on this topic.

In this research, the future changing trend of NWI is of concern. The grey forecasting theory [1] is one of the suitable tools to achieve the goal as limited data provided. Grey theory has been developing for more than 30 years and has progressed greatly recently because of many contributors working on this subject. Huang et al. [2] used the Artificial Fish Swarm Algorithm to dynamically adjust the parameters of the Gray Model Neural Network to enhance the precision of the stock forecast model as a whole. The result showed that the forecast capability of each stage after the optimization process is better than that of its previous stage, and the mixed stock forecast model (GPAFSA+GMNN-AFSA) in stage 4 greatly enhanced the precision of the forecast. Hsin and Chen [3] combined game theory with NGBM to the forecasting of Taiwan's GDP. The results show that five elements in raw data sequence are optimal topological length for constructing NNGBM in the case of Taiwan's GDP forecasting. Topics about energy related economic indicators are one of the most concern. Kankal et al. [4] modeled the energy consumption in Turkey in order to forecast future projections based on socio-economic and demographic variables (gross domestic product-GDP, population, import and export amounts, and employment) using artificial neural network (ANN) and regression analyses. Finally, it was concluded that all the scenarios that were analyzed gave lower estimates of the energy consumption than the MENR projections and these scenarios also showed that the future energy consumption of Turkey would vary between 117.0 and 175.4 Xie [5] applied an optimized single-variable discrete grey forecasting model [OSDGM $(1,1)]$ to measure the instigation effects of the energysaving policy and forecast whether the planned reduction rate of energy consumption per unit GDP in the implementation stage could be accomplished or not. The results illustrate that China's government has made major progress on energy saving even though the task is tough in the long run. Aydin [6] modeled Turkey's primary energy consumption by regression analysis (RA) based on population (CP) and gross domestic product (GDP). The derived model is validated by various statistical approaches. The results show that the proposed model can be affectively used for forecasting of Turkey's PEC. The scenarios also show that the future energy consumption of Turkey would vary between 174.65 and 203.13. Various researchers also worked on these topics [7-13].

Grey theory has been successfully applied to forecast various economic indicators. In this research, the newly complied National Well-being Indicators in Taiwan since 2013 is of research interest. The characteristics of less data needed for grey theory is adopted to forecast the NWI of Taiwan to show the future changing trend.

*Corresponding author: Chen $\mathrm{Cl}$, Department of Industrial Management, I-Shou University, Taiwan, Tel: +886-7-6577711; E-mail: eddyChen@isu.edu.tw

Received December 01, 2015; Accepted January 19, 2016; Published January 22, 2016

Citation: Huang CY, Lo YY, Chen Cl (2016) Forecasting National Well-being Indicators of Taiwan. J Glob Econ 4: 174. doi:10.4172/2375-4389.1000174

Copyright: ( 2016 Huang CY, et al. This is an open-access article distributed under the terms of the Creative Commons Attribution License, which permits unrestricted use, distribution, and reproduction in any medium, provided the original author and source are credited. 


\section{Mathematical Methodology of Nonlinear Grey Ber- noulli Model}

The first order linear differential equation is the theoretical basis of grey forecasting model. The solution curve could fit the collected data by means of least square method. The characteristics of exponential function could provide more flexibility of fitting than linear regression model.

\section{Traditional grey model GM $(1,1)$}

This section provides the derivation of traditional grey forecasting in detail [14].

Step 1: Assume that the original series of data with $m$ entries is:

$$
X^{(0)}=\left\{x^{(0)}(1), x^{(0)}(2), \ldots, x^{(0)}(k), . ., x^{(0)}(m)\right\}
$$

where raw matrix $X^{(0)}$ stands for the non-negative original historical time series data.

Step 2: Construct $X^{(1)}$ by one time accumulated generating operation (1-AGO), which is

$$
X^{(1)}=\left\{x^{(1)}(1), x^{(1)}(2), \ldots, x^{(1)}(k), \ldots, x^{(1)}(m)\right\}
$$

where

$$
x^{(1)}(k)=\sum_{i=1}^{k} x^{(0)}(i), k=1,2, \ldots, m \text {. }
$$

Step 3: The result of 1-AGO is monotonic increase sequence which is similar to the solution curve of first order linear ordinary differential equation. Therefore, the solution curve of following differential equation represents the approximation of 1-AGO data.

$$
\frac{d \hat{X}^{(1)}}{d t}+a \hat{X}^{(1)}=b
$$

where $\wedge$ represents Grey forecast value. The $a$ and $b$ are model parameters and $a$ could not equal to zero [14]. $x \quad(1)=x^{(0)}(1)$ is the corresponding initial condition.

Step 4: The model parameters $a$ and $b$ can be determined by discrete form of Eq. (4)

$$
\frac{d \hat{X}^{(1)}}{d t}=\lim _{\Delta t \rightarrow 0} \frac{\hat{X}^{(1)}(t+\Delta t)-\hat{X}^{(1)}(t)}{\Delta t}
$$

If the sampling time interval is unit, then let $\Delta \rightarrow$

$$
\begin{aligned}
& \frac{d \hat{X}^{(1)}}{d t} \cong x^{(1)}(k+1)-x^{(1)}(k)=x^{(0)}(k+1), k=1,2,3, \\
& \quad \text { and } \hat{X}^{(1)}(t) \text { is defined as } \\
& \hat{X}^{(1)}(t) \cong P x^{(1)}(k)+(1-P) x^{(1)}(k+1)=z^{(1)}(k+1, k=1,2,3,
\end{aligned}
$$

where $z^{(1)}$ is termed background value, $P$ is traditionally set to 0.5 . The source model then can be obtained as

$$
x^{(0)}(k)+a z^{(1)}(k)=b, k=2,3,4,
$$

From Eq. (8), by least square method, the model parameters $a$ and $b$ are

$$
\left[\begin{array}{l}
a \\
b
\end{array}\right]=\left(B^{T} B\right)^{-1} B^{T} Y_{N}
$$

where $B$ and $Y_{N}$ are defined as follows

$$
B=\left[\begin{array}{cc}
-z^{(1)}(2) & 1 \\
-z^{(1)}(3) & 1 \\
\vdots & \vdots \\
-z^{(1)}(m) & 1
\end{array}\right], \quad Y_{N}=\left[\begin{array}{c}
x^{(0)}(2) \\
x^{(0)}(3) \\
\vdots \\
x^{(0)}(m)
\end{array}\right] \text {, }
$$

or, $a$ and $b$ can be expressed in the following form

$$
\begin{aligned}
& a=\frac{\sum_{k=2}^{m}\left[z^{(1)}(k)\right] \sum_{k=2}^{m} x^{(0)}(k)-(m-1) \sum_{k=2}^{m} x^{(0)}(k) z^{(1)}(k)}{(m-1) \sum_{k=2}^{m}\left[z^{(1)}(k)\right]^{2}-\left(\sum_{k=2}^{m} z^{(1)}(k)\right)^{2}} \\
& b=\frac{\sum_{k=2}^{m} x^{(0)}(k) \sum_{k=2}^{m}\left[z^{(1)}(k)\right]^{2}-\sum_{k=2}^{m} x^{(0)}(k) z^{(1)}(k) \sum_{k=2}^{m} z^{(1)}(k)}{(m-1) \sum_{k=2}^{m}\left[z^{(1)}(k)\right]^{2}-\left(\left.\sum_{k=2}^{m} z^{(1)}(k)\right|^{2}\right.}
\end{aligned}
$$

Step 5: Solve the Eq. (4) together with initial condition, and the particular solution is

$$
\hat{X}^{(1)}(k+1)=\left(x^{(0)}(1)-\frac{b}{a}\right) e^{-a k}+\frac{b}{a}, k=1,2,3, \ldots \ldots,
$$

Hence, the desired forecasting output at $k$ step can be estimated by inverse accumulated generating operation (IAGO) which is defined as

$$
\hat{x}^{(0)}(k+1)=\left(1-e^{-a}\right)\left(x^{(0)}(1)-\frac{b}{a}\right) e^{-a k}, k=1,2,3, \ldots \ldots
$$

\section{Error analysis}

Error analysis is needed for examining the precision of forecasted results. Relative percentage error (RPE) compares the real and forecast values to evaluate the precision at specific time $k$. RPE is defined as

$$
\mathrm{RPE}=\varepsilon(k)=\frac{x^{(0)}(k)-x^{(0)}(k)}{x^{(0)}(k)} \times 100 \%, k=2,3,4, \ldots, m,
$$

where $x \quad(k)$ is the actual value and $x \quad(k)$ is the forecasted value by Eq. (14). The total model precision can be defined by average relative percentage error (ARPE) as follows

$$
\mathrm{ARPE}=\varepsilon(\operatorname{avg})=\frac{1}{m-1} \sum_{k=2}^{m}|\varepsilon(k)|, k=2,3,4, \ldots, m .
$$

\section{Forecasting National Well-being Indicators by GM $(1,1)$}

Among the 11 topics shown in Table 1, there are three indicators which are direct economic related and provided with complete five years information. These indicators are consumption expenditure per capita, unemployment rate of age 15 to 24 and real earning. Following, these three indicators are analyzed by $\operatorname{GM}(1,1)$ to show the future four years developing trend. The results could provide the government direction of proposing policies.

\section{Consumption expenditure per capita}

Consumption expenditure per capita is defined as household consumption expenditure divided by number of family member. This indicator is objective because it is calculated from collected statistical data and is positive because it is better to have higher figure. From the data from year 2010 to 2014, the figure gradually increases from NT 216,090 to 239,736 which show the positive economic development. The forecast value from year 2015 to 2018, it also shows positive direction. The modelling error is only $0.32 \%$ and highest point residual 


\begin{tabular}{|c|c|c|}
\hline Topics & International Indicators & Domestic Indicators \\
\hline \multirow[t]{5}{*}{ Housing conditions } & Rooms per person & Average dwelling space per person \\
\hline & Housing expenditure & Ratio of house price to income \\
\hline & Dwelling without basic facilities & Ratio of rent to income \\
\hline & & Satisfaction with present dwelling \\
\hline & & Satisfaction with dwelling surrounding environment quality \\
\hline \multirow[t]{5}{*}{ Income and Wealth } & Household net adjusted disposable income(PPP) & Annual change rate of median disposable income per capita \\
\hline & \multirow[t]{4}{*}{ Household financial wealth(PPP) } & Consumption expenditure per capita \\
\hline & & Ratio of income share of highest $20 \%$ to that of lowest $20 \%$ \\
\hline & & Subjective evaluation of material wellbeing \\
\hline & & Ratio of relative poverty \\
\hline \multirow[t]{4}{*}{ Jobs and Earnings } & Employment rate & Ratio of part-time, temporary or dispatched workers \\
\hline & Long-term unemployment rate & Unemployment rate of age 15 to 24 \\
\hline & Personal earnings(PPP) & Satisfaction with Jobs \\
\hline & Job security & Real earning \\
\hline \multirow[t]{5}{*}{ Social connections } & \multirow[t]{5}{*}{ Quality of support network } & Frequency of socializing with friends \\
\hline & & Frequency of socializing with relatives \\
\hline & & Time spent volunteering \\
\hline & & Trust in others \\
\hline & & Satisfaction with family relationship \\
\hline \multirow[t]{3}{*}{ Education and skills } & Educational attainment & Lifelong learning \\
\hline & Years in education & \\
\hline & Students' skills in maths, reading and science & \\
\hline \multirow[t]{2}{*}{ Environmental quality } & Air pollution & Average green spaces per person in the urban area \\
\hline & Water quality & Participation in political activities \\
\hline \multirow{5}{*}{$\begin{array}{l}\text { Civic engagement and } \\
\text { governance }\end{array}$} & Voter turnout & Confidence in national government \\
\hline & \multirow[t]{4}{*}{ Consultation on rule-making } & Confidence in judicial system and courts \\
\hline & & Confidence in media \\
\hline & & Satisfaction with democratic life \\
\hline & & Satisfaction with the freedom of speech \\
\hline \multirow[t]{5}{*}{ Health status } & Life expectancy & Self-reported limitations in daily activities \\
\hline & \multirow[t]{4}{*}{ Self-reported health } & Caregiver's burden \\
\hline & & Healthy life expectancy \\
\hline & & Percentage of rejection cases in food inspection and test \\
\hline & & Foodborne Illness \\
\hline \multirow[t]{2}{*}{ Subjective well-being } & \multirow[t]{2}{*}{ Life satisfaction(Cantril Ladder) } & Life satisfaction \\
\hline & & Characteristics contribute to Taiwan's well-being \\
\hline \multirow[t]{4}{*}{ Personal security } & Homicide rate & Victim of domestic violence \\
\hline & Assault rate & Occurrence of residential burglary \\
\hline & Mortality from accidents & \\
\hline & Feeling of security & \\
\hline \multirow[t]{2}{*}{ Work and life balance } & Employees working very long hours & Commuting time \\
\hline & Time devoted to leisure and personal care & Satisfaction with allocation of time \\
\hline
\end{tabular}

Note: 1The international indicators are based completely on OECD Your Better Life Index.

2 No total score will be added up for the domestic indicators.

Source: http://happyindex.dgbas.gov.tw/e_index.htm?y=201506

Table 1: The national well-being indicators in Taiwan.

error is $0.62 \%$. This shows high reliability of forecasting result. From the figure, it is believed the economic situation is still on track to the bright side. The forecasting is shown in Table 2.

\section{Unemployment rate of age 15 to 24}

Unemployment rate of age 15 to 24 is defined as total number of unemployment versus total number of labors in the age range. This indicator is also objective because it is calculated from collected statistical data and is negative because it is better to have lower figure. During the past five years, the unemployment rate of age 15 to 24 is kept on the high proportion rate from $12.59 \%$ to $13.09 \%$. The reason might be the people in this age range are still in the school from junior high to university. The rate is forecast to be still high value because of this same reason. And this figure will be worse because of low birth rate in Taiwan. In the future four years, this indicator always is kept above $13 \%$. The modelling error is only $1.51 \%$ and highest point residual error is $2.95 \%$. The forecast result is shown in Table 2 .

\section{Real earning}

Real earning is defined as average salary minus commodity price fluctuation. This indicator is objective because it is calculated from collected statistical data and is positive because it is better to have higher figure. From the past five years, the real earning is kept almost unchanged and even having trend of decline. In the future four years, the forecast real earning is decreasing year by year. This might be economic downturn or soaring commodity price. The direct feeling of 
Page 4 of 4

\begin{tabular}{|c|c|c|c|c|c|c|c|c|c|c|}
\hline Indicators & units & 2010 & 2011 & 2012 & 2013 & 2014 & 2015 & 2016 & 2017 & 2018 \\
\hline $\begin{array}{l}\text { Consumption } \\
\text { expenditure per capita }\end{array}$ & NT dollar & 216,090 & 221,584 & 225,292 & 232,998 & 239,736 & & & & \\
\hline Forecast value & NT dollar & 216,090 & 220627 & 226,688 & 232,917 & 239,317 & 245,892 & 252,648 & 259,590 & 266,723 \\
\hline RPE & $\%$ & 0 & 0.43 & -0.62 & 0.03 & 0.17 & & & & \\
\hline ARPE (\%) & $\%$ & \multicolumn{5}{|c|}{0.32} & & & & \\
\hline $\begin{array}{l}\text { Unemployment rate of } \\
\text { age } 15 \text { to } 24\end{array}$ & $\%$ & 13.09 & 12.47 & 12.66 & 13.17 & 12.63 & & & & \\
\hline Forecast value & $\%$ & 13.09 & 12.59 & 12.68 & 12.78 & 12.88 & 12.98 & 13.08 & 13.18 & 13.28 \\
\hline RPE & $\%$ & 0 & -0.93 & -0.18 & 2.95 & -1.97 & & & & \\
\hline ARPE & $\%$ & \multicolumn{5}{|c|}{1.51} & & & & \\
\hline Real earning & NT dollar & 44,989 & 45,508 & 44,726 & 44,446 & 45,494 & & & & \\
\hline Forecast value & NT dollar & 44,989 & 45,092 & 45,059 & 45,027 & 44,995 & 44,962 & 44,930 & 44,898 & 44,865 \\
\hline RPE & $\%$ & 0 & 0.91 & -0.75 & -1.31 & 1.10 & & & & \\
\hline ARPE & $\%$ & \multicolumn{5}{|c|}{1.02} & & & & \\
\hline
\end{tabular}

Source: http://happyindex.dgbas.gov.tw/e_index.htm?y=201506

Table 2: Actual and forecast value of three economic related indicators.

people is based on what they actual face. The real earning decline will of course cause complaint from people. The government should make effort to urge boss to raise up salary in order to subside people's anger. The modelling error is only $1.02 \%$ and highest point residual error is $1.31 \%$. The forecast result is shown in Table 2 .

\section{Conclusion}

The current official statistical figures are far reaching the heart of people. The positive economic performance could not win applause from people. In order to close to people real life, Taiwan government proposed National Well-being Indicators to actually reflect people's life based on the everyday life statistics. There are two categories and 11 indicators. In this research, three indicators are forecast by grey forecasting model to show their future changing trend. The result showed that forecasting precision is very high. The consumption expenditure per capita will be kept increasing owing to high commodity price, Unemployment rate of age 15 to 24 will also be kept at high value because of 12 year compulsory education and low birth rate, real earning will be lowering which might be the sign of recession in economic. These results could provide the government to propose new policy in advance to prevent future deteriorating economic situation.

\section{Acknowledgement}

The authors would like to thank for financial support from Ministry of Science and Technology under the contract MOST Project NO 104-2221-E-214-037 and I-Shou University, under the contract NO ISU 104-03-01A.

\section{References}

1. Deng JL (1982) Control problems of grey systems. Systems and Control Letters 1: 288-294.

2. Huang CJ, Chen PW, Pan WT (2012) Using multi-stage data mining technique to build forecast model for Taiwan stocks. Neural Computing and Applications 21: 2057-2063.

3. Hsin $\mathrm{PH}$, Chen $\mathrm{Cl}$ (2015) Application of game theory on parameter optimization of the novel two-stage Nash nonlinear grey Bernoulli model. Communications in Nonlinear Science and Numerical Simulation 27: 168-174.

4. Kankal M (2011) Modeling and forecasting of Turkey's energy consumption using socio-economic and demographic variables. Applied Energy 88: 1927-1939.

5. Xie NM, Pearman AD (2014) Forecasting energy consumption in China following instigation of an energy-saving policy. Natural Hazards 74: 639-659.
6. Aydin G (2014) Modeling of energy consumption based on economic and demographic factors: The case of Turkey with projections. Renewable and Sustainable Energy Reviews 35: 382-389

7. Wang JZ (2011) Coal production forecast and low carbon policies in China Energy Policy 39: 5970-5979.

8. Pao HT, Fu HC, Tseng CL (2012) Forecasting of CO2 emissions, energy consumption and economic growth in China using an improved grey model. Energy 40: 400-409.

9. Zhao Z (2012) Using a Grey model optimized by Differential Evolution algorithm to forecast the per capita annual net income of rural households in China. Omega-International Journal of Management Science 40: 525-532.

10. Lee YS, Tong LI (2012) Forecasting nonlinear time series of energy consumption using a hybrid dynamic model. Applied Energy 94: 251-256.

11. Pan WT (2012) The use of genetic programming for the construction of a financial management model in an enterprise. Applied Intelligence 36: 271-279.

12. Yu SW, Zhu KJ (2012) A hybrid procedure for energy demand forecasting in China. Energy 37: 396-404.

13. Wang MW (2014) A Novel Clustering Model Based on Set Pair Analysis for the Energy Consumption Forecast in China. Mathematical Problems in Engineering.

14. Chen Cl, Huang SJ (2013) The necessary and sufficient condition for GM $(1,1)$ grey prediction model. Applied Mathematics and Computation 219: 6152-6162. 